\title{
Using of Peer Assisted Learning to Conduct Pre-Training Situational Analysis for Nurse Intern Rabab Abdel Ra'oof Abed ${ }^{182}$, Nada H. Gomma ${ }^{3}$ and Asmaa Abdel Nasser ${ }^{124 *}$

\author{
'Medical Education Department, Faculty of Medicine, Suez Canal University, Postal code: 21461, Egypt; \\ dr.rababraoof@gmail.com, dr.asmaaabdelnasser@gmail.com \\ 2Medical Education Department, Fakeeh College of Medical Sciences, Jeddah, KSA \\ ${ }^{3}$ Nursing Department, Fakeeh College of Medical Sciences, Jeddah, KSA \\ ${ }^{4}$ Medical Education Unit, Ibn Sina National College, Jeddah, KSA
}

\begin{abstract}
Background: Clinical placement is the main site for interns' training, however clinical placement is an uncomfortable and inconvenient environment for learning. Trainees need intelligent conversation with self and others to advance in their careers. In this regard, Peers informally teach each other through discussion. Nowadays, there is an international need and interest in formal peer-assisted learning. Hence, Situational model for curriculum development is a suitable model for training as it is culturally driven and emphasizes context. The research objectives are to apply a situational curricular model, using a peerassisted learning. In addition, to explore the students' perception towards peer-assisted learning. Methods: A mixed method quantitative and qualitative design single group post-test design was applied in this study, where all the nursing interns in the current year were selected. Peers conducted orientation sessions to make situational analysis. After that, each intern, with his educational supervisor, develops personal objectives and a development plan. Selection of contents and learning opportunities is the responsibility of interns guided by the general outcomes and list of required competencies during the training year. The last step is assessment and evaluation of performance. Furthermore, interns' perceptions towards using peers-assisted learning were measured through distribution of self-administered questionnaire, and conduction of focus group with interns. Results: Overall students' perceptions toward this reform were positive, all means were above four, especially their perception towards Peer Assisted Learning (PAL) as a relaxed and comfortable environment and as a new learning opportunity. Conclusion: Interns found that reform of their training through conducting situational model for training is an effective method, especially when using Peer Assisted Learning (PAL) in its conduction, which, they recommended its implementation to all units' orientation
\end{abstract}

Keywords: Curricular Situational Model, Internship, Peer-Assisted Learning

\section{Introduction}

Internship year is a transitional period between graduation and registration for full practice, as defined by Paice et al. $(2002)^{1}$, the internship year follows the graduation and precedes registration for full practice.

All training and learning occur through clinical teachings, which mean learning that involves patient and their problems (Spencer, 2003) ${ }^{2}$. It gives the opportunity to put into practice knowledge and skills that have been learnt in undergraduate curricula, additionally it enables trainees to show confidence in performing competencies those are required to be fully registered practitioner (Spencer, 2003) ${ }^{2}$.
Training occurs mainly in clinical placement, nevertheless clinical placement, as a learning organization, has its challenges as being uncomfortable and inconvenient environment for learning, to foster learning experience in this environment, trainees need intelligent conversation with them self and others to advance in their careers. This will happen through reflective practice, supervision, and team discussion (Tim Swanwick, 2014) ${ }^{3}$.

Situational model for curriculum development, which is firstly addressed by Malcolm Skilbeck, is culturally driven and emphasizes context for designing curriculum; In this study, it is the internship training (David Prideaux, 2003) ${ }^{4}$.

First, Curriculum designer analyze the situation they will work thoroughly, by assessing the implication of both

*Author for correspondence 
external and internal factors on the curriculum. This is followed by statement of intent, which includes formulation of goals and objectives, then they build the program, and then implement and organize it, and finally they evaluate and assess the whole processes. No need to follow a particular order for application of these steps but they affect each other (David Prideaux, 2003; Marian, 2013) ${ }^{4,5}$.

Peers informally teach each other through discussion, but now there is more international need and interest in formal well-structured peer-assisted learning. Peer-assisted learning has been proven in literature as a useful tool for learning, additionally, for developing competence in areas such as lifelong learning, and teaching skills which are now required within many health professional framework. PAL is a useful method to promote group interactions, it provides more comfortable environment for discussion and it increases self-confidence, motivation, and students' responsibility for their own learning (Harish \& Nicola, 2017) $)^{6}$.

Peers are similar social group to the learners, and they are not professional educators as they have less experience, teaching skills, and authority than the experienced tutors do (Michael \& Helen, 2007) ${ }^{7}$. Peer Assisted Learning enhances learning through demonstrating cognitive congruence, which means delivering teaching at an appropriate level of learners and satisfying their needs, Furthermore, it provides social congruence through learning in non-threatening environment with less authority of peers, whereby learners ask questions and admit weaknesses (Harish \& Nicola, 2017) $)^{6}$.

This research aims at enhancing clinical training of nurse interns (house officer) through applying a situational

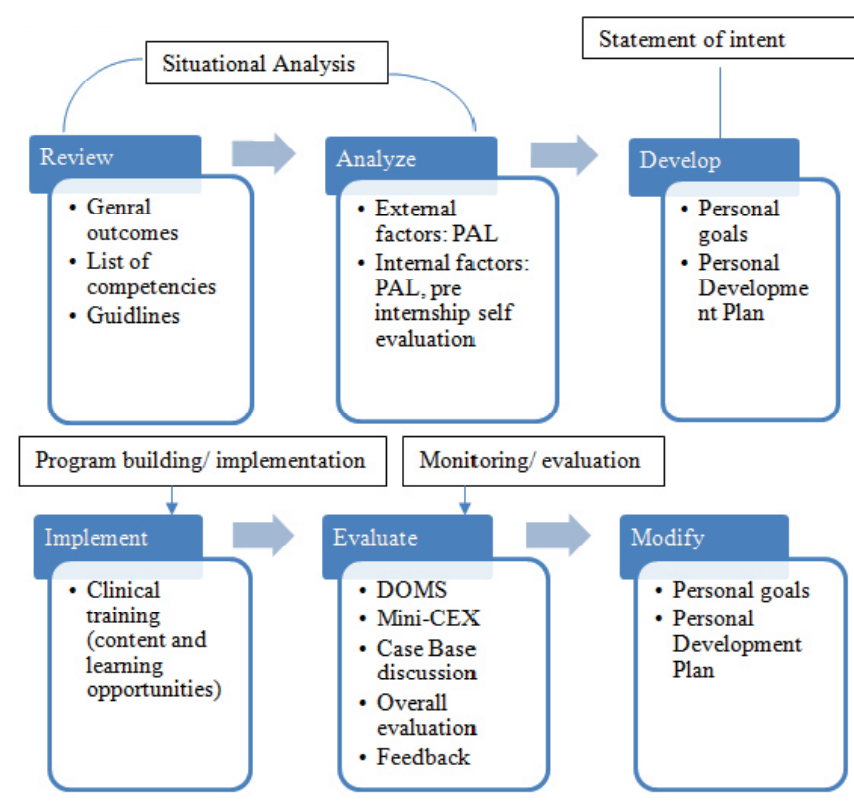

Figure 1. Implementing Situational Model for Internship Training Program. curricular model through implementing a peer-assisted learning. In addition, explore the students' perception and satisfaction towards peer-assisted learning.

\section{Methods}

\subsection{Study Context and Sampling}

A mixed quantitative and qualitative method single group post-test design was applied in this study, where peer assisted learning implemented as a small group discussion for BSN interns $(\mathrm{n}=33)$ using a comprehensive sampling technique. The main purpose for Peer Assisted Learning (PAL) is to help peers intern to analyze external and internal factors which will improve their reflection and personal development plan. Their perceptions were measured through distribution of self-administered questionnaire. Focus group meeting was conducted to get in depth insight of the effect of PAL in unit orientation. Their participation was recorded and transcribed then underwent thematic analysis to identify themes.

\subsection{Structure and Implementation}

In the first week of training, interns receive training handbook and portfolio, they review the general outcomes and a list of required competencies, and then they conduct situational analysis for the environment they will work within it. Interns perform with peers analysis of external factors by conducting PAL unit orientation for nurse interns at the beginning of each rotation (Figure 1\&2).

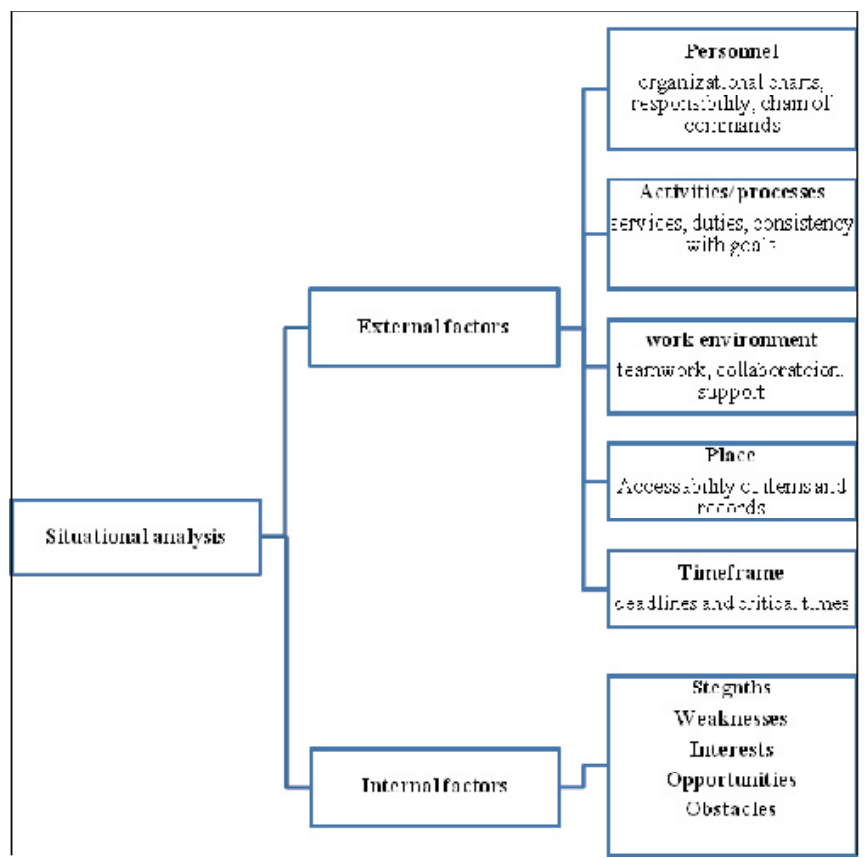

Figure 2. External and internal factors of the situational analysis model. 
PAL was implemented as a small group discussion, where students' number ranged from four to six for each group. We distributed among them a unit orientation checklist to use it as a guide for their sessions. They discussed with their peers the requirements of the unit in terms of personnel, activities, processes, environment, timeframe, place, and equipment. Furthermore, they discussed with them learning opportunities available and obstacles those they faced during their training. Later, interns use pre internship self-evaluation tool to analyze internal factors in terms of their strengths, weaknesses and interest in three domains which are; nurse care management, interpersonal relationship and communication, and professionalism.

First we trained peers how to tackle this activity, then we measured their perception through distributing selfadministered questionnaires to measure their satisfaction and to evaluate this activity in enhancing their performance.

Interns use the results of external and internal factor analysis to develop Personal Development Plan (PDP), with guidance of their educational supervisor by the end of the first week. The intern should implement this PDP under the supervision of the educational supervisor and guidance from the clinical preceptor, then they should conduct DOPS (Direct Observation of Procedural Skills), and Mini-CEX (Mini Clinical Exercise Exam) and Case Base Discussion (CBD)with the preceptor to check the intern progress, and finally modify his/her personal plan if needed.

\subsection{Study Instruments}

We designed a questionnaire, which is updated from Usman R, Jamil B, 2019, to measure the satisfaction of the students regarding this new instructional method. Interns' perception was measured using a 5-point Likert-type scale ( 5 = strongly agree, $1=$ strongly disagree). This scale included items such as; satisfaction, benefits, interaction and motivation, the effects on enhancing presentation and communication skills, self-confidence, and teaching skills (Usman \& Jamil, 2019) .

One focus group was conducted after completing PAL orientation session, interns' participation was voluntary. It was conducted in the break time to not interfere with their duties. 23 out of 33 participants agreed to participate in the focus group (response rate $70 \%$ ). Interns were asked about their feeling in this learning environment, if they were comfortable and relaxed to share ideas and ask questions, about their peers teaching skills and manner, information they have acquired regarding challenges and learning opportunities, and how this helped them to begin their training and to reflect on their previous performance, then write their reflection and develop personal development plan. Furthermore, they were asked about their role as a tutor.

\subsection{Statistical Analysis}

Data analysis was performed using the Statistical Package for the Social Sciences (SPSS, version 20. IBM). Descriptive statistics were used for analyzing study findings. Means, standard deviations, and frequencies were used for presenting the data from the questionnaire. Internal consistency (reliability) of the questionnaire was measured using Cronbach's Alpha. Focus group discussion was audiotaped and transcribed and discussed with interns to confirm data and make clarification. Transcripts underwent thematic analysis where codes were identified and get consensus of researchers.

\subsection{Ethical Considerations}

Ethical clearance for the study was obtained and approved by the IRB of "Fakeeh College of Medical Sciences (FCMS). During the implementation phase, the participants were all informed about the purpose of the study and their right to refuse participation. Ethical conduct was maintained during data collection and throughout the research process. Participation in the study was voluntary and the confidentiality of the participants was maintained.

\section{Results}

We used descriptive analysis to analyze data, frequency and percentages were calculated, and mean and standard deviation were measured for each question. Overall students' perceptions toward this strategy was positive, most of their answers ranged between agree and strongly agree; all means were above four. The most agreed upon factors were seeing PAL as an environment that makes them feel relaxed and comfortable, and as a teaching method providing new and relevant learning opportunities, and it was a beneficial teaching experience. Interns' responses regarding if they felt PAL enhanced their teaching skill and clinical knowledge, ranged between not sure and strongly agree, however, the mean was above 4 (Table 1).

The reliability of the questionnaire was 0.99 , using Cronbach Alpha test, which reflects high internal consistency of the questionnaire.

More than $82 \%$ of the students answered these questions as "agree or strongly agree", except one item which is "if they see comparing their work with others was motivating", only $78 \%$ agreed upon this question (Table $2 \& 3$ ). 
Table 1. The interns perceptions towards pear assisted learning $(n=33)$

\begin{tabular}{|c|c|c|c|}
\hline No & Perception of PAL & Mean & Standard Deviation (SD) \\
\hline A & As a tutee (listener) & & \\
\hline 1 & It was an interesting activity & 4.434 & 1.375 \\
\hline 2 & I feel relaxed to ask questions & 4.478 & 1.377 \\
\hline 3 & My peer manner match my level of understanding & 4.391 & 1.373 \\
\hline 4 & It was an interactive session & 4.391 & 1.405 \\
\hline 5 & The session was relevant to real experience & 4.478 & 1.377 \\
\hline 6 & They respond to my concerns & 4.434 & 1.375 \\
\hline 7 & They understand problems and challenges faced us & 4.434 & 1.375 \\
\hline 8 & It was motivating to compare yourself with others & 4.347 & 1.335 \\
\hline 9 & I was comfortable to share my ideas & 4.478 & 1.377 \\
\hline 10 & I feel easy to communicate with peer as compared to nurse manger & 4.347 & 1.368 \\
\hline 11 & I recommend this method to all unit orientation & 4.391 & 1.373 \\
\hline 12 & I found it was more informative than classical unit orientation & 4.391 & 1.373 \\
\hline 13 & I found the teacher role of peers was effective & 4.347 & 1.401 \\
\hline 14 & This provided me with new learning opportunities & 4.478 & 1.377 \\
\hline 15 & In general, I found it an effective method & 4.434 & 1.375 \\
\hline B & As a tutor & & \\
\hline 1 & This decreased my anxiety to present in front of others & 4.347 & 1.401 \\
\hline 2 & It enhanced my communication skills & 4.304 & 1.550 \\
\hline 3 & This improved my clinical knowledge & 4.217 & 1.536 \\
\hline 4 & It enhanced my teaching skills & 4.217 & 1.536 \\
\hline 5 & It was a beneficial experience of teaching for me & 4.478 & 1.377 \\
\hline 6 & This helped me to review and reflect on my previous unit experience & 4.434 & 1.375 \\
\hline
\end{tabular}

Table 2. The Frequency of Agreement among the Nurse Internstowards the Peer Assisted Learning $(n=33)$

\begin{tabular}{|c|c|c|c|c|}
\hline No & Perception of PAL & Disagree & Not Sure & Agree \\
\hline A & As a tutee (listener) & & & \\
\hline 1 & It was an interesting activity & $13.20 \%$ & $1.00 \%$ & $85.80 \%$ \\
\hline 2 & I feel relaxed to ask questions & $11.00 \%$ & $2.00 \%$ & $87.00 \%$ \\
\hline 3 & My peer manner match my level of understanding & $19.10 \%$ & $0.00 \%$ & $80.90 \%$ \\
\hline 4 & It was an interactive session & $13.40 \%$ & $4.00 \%$ & $82.60 \%$ \\
\hline 5 & The session was relevant to real experience & $13.00 \%$ & $0.00 \%$ & $87.00 \%$ \\
\hline 6 & They respond to my concerns & $13.10 \%$ & $00.00 \%$ & $86.90 \%$ \\
\hline 7 & They understand problems and challenges faced us & $13.10 \%$ & $00.00 \%$ & $86.90 \%$ \\
\hline 8 & It was motivating to compare yourself with others & $12.50 \%$ & $05.00 \%$ & $82.50 \%$ \\
\hline 9 & I was comfortable to share my ideas & $13.00 \%$ & $00.00 \%$ & $87.00 \%$ \\
\hline 10 & I feel easy to communicate with peer as compared to nurse manger & $13.1 \%$ & $00.00 \%$ & $85.90 \%$ \\
\hline 11 & I recommend this method to all unit orientation & $13.00 \%$ & $00.00 \%$ & $87.00 \%$ \\
\hline 12 & I found it was more informative than classical unit orientation & $13.00 \%$ & $00.00 \%$ & $87.00 \%$ \\
\hline 13 & I found the teacher role of peers was effective & $08.70 \%$ & $08.70 \%$ & $82.60 \%$ \\
\hline 14 & This provided me with new learning opportunities & $10.00 \%$ & $00.00 \%$ & $90.00 \%$ \\
\hline 15 & In general, I found it an effective method & $13.10 \%$ & $00.00 \%$ & $86.90 \%$ \\
\hline
\end{tabular}




\begin{tabular}{|c|c|c|c|}
\hline B & As a tutor (facilitator) & & \\
\hline 1 & This decreased my anxiety to present in front of others & $12.30 \%$ & $05.10 \%$ \\
\hline 2 & It enhanced my communication skills & $21.40 \%$ & $00.00 \%$ \\
\hline 3 & This improved my clinical knowledge & $17.40 \%$ & $00.00 \%$ \\
\hline 4 & It enhanced my teaching skills & $17.40 \%$ & $00.00 \%$ \\
\hline 5 & It was a beneficial experience of teaching for me & $13.00 \%$ & $00.00 \%$ \\
\hline 6 & This helped me to review and reflect on my previous unit experience & $13.10 \%$ & $82.60 \%$ \\
\hline & & & $86.00 \%$ \\
\hline
\end{tabular}

Note: Results of strongly agree and agree are combined

Table 3. Themes of the focus group discussionwith the participating interns regarding the peer assisted learning $(\mathrm{n}=23)$

\begin{tabular}{|c|c|}
\hline Themes & Comments \\
\hline Overall satisfaction & $\begin{array}{l}\text { All interns recommended PAL to be a method of teaching for unit orientation. They found it interesting } \\
\text { and very interactive. It was more informative for them than ordinary unit orientation. } \\
\text { "It was a very fruitful discussion everybody shared in the discussion." }\end{array}$ \\
\hline Peers teaching skills & $\begin{array}{l}\text { Most of interns said that their peers were talking at the same level of their understanding, they all } \\
\text { agreed that peers discussed all concerns and inquiries before the beginning of their training. They } \\
\text { addressed all challenges and problems those might face them during their training. } \\
\text { "They answered questions in my mind, and they answered exactly what I want to know" }\end{array}$ \\
\hline Environment & $\begin{array}{l}\text { The atmosphere was relaxing and trustworthy most of time, and this improved their participation, they } \\
\text { felt comfortable to ask questions and share ideas. The presence of senior nurses renders them from } \\
\text { asking some questions. } \\
\text { "In ordinary session I am feeling shy to ask some questions that make me silly in front of doctors and peers, } \\
\text { but in PAL I felt that I am talking to my friends, so I can say anything at any time". }\end{array}$ \\
\hline Impact & $\begin{array}{l}\text { PAL improved interns' skills for writing their reflection and developing their personal plan which in } \\
\text { turn affects their overall clinical knowledge, on the other hand, PAL enhance their teaching skills and } \\
\text { presentation in front of others. } \\
\text { "Writing reflection is a difficult mental task especially at the beginning of training, but having discussion } \\
\text { with my peers helped me a lot" } \\
\text { "I always find difficulty to talk in front of others but talking with my peers on my experience increased my } \\
\text { self-confidence" }\end{array}$ \\
\hline
\end{tabular}

\section{Discussion}

The internship year is a transitional year between undergraduate education and licensing to practice. Interns are distributed among different units with different life experience, thus training in this year is contextual and even chaotic most of times.

We found that we need to link training to its context and to emphasize personal needs. There are many curriculum models those emphasize processes rather than contents or outcomes, where learning should be contextualized and personalized to suit each individual student's needs (Kelly, 2004) ${ }^{9}$. Postmodern curriculum explains that each student develops his own learning experience; as it sees learning as a natural, chaotic, and nonlinear process, and everything outside the student is a stimulus to discover his strengths and interest, and to identify his weaknesses and obstacles (Dyah, 2018) $^{10}$.
Another model is situational curricular model, sometimes called school-based curriculum, it emphasizes culture and context of learning, and it also does not follow linear pattern. It reflects three principles; student's freedom to develop his own learning experience, school environment is a human social institution, and finally staff should consider development to adapt to individual learning needs (adaptive learning) (Kelly, 2004) .

Situational analysis is a cornerstone in this model; it includes analyzing external and internal factors. External factors related to the learning environment in terms of personnel, processes, resources...etc. while internal factors focus on learning needs and potentials (David Prideaux, $2003)^{4}$.

Learning occurs mainly through group discussion, supervision, and reflective practice (Tim Swanwick, $2014)^{3}$. Vygotsky elaborated social constructivism theory which states that learners understanding and meaning 
increase through social encounter with expert guidance and peers collaboration (David, 2010) ${ }^{11}$. We can see that discussion among peers is a main strategy for learning in any community of practice. Hence, we conducted this study to enhance nursing interns' learning experience through discussion with peers in a systematic manner.

Firstly, we implemented this strategy on a small scale as a small group discussion at the beginning of each rotation. Small group discussion is an effective teaching strategy to implement PAL, where SGD increases interactivity among group members because students are more accountable to be prepared and participate in a small group (Andrew et al., 2016) ${ }^{12}$.

Most of students were satisfied with this activity as they felt that they were more comfortable and relaxed to ask questions to peers. Furthermore, it was easy to communicate with others. Many studies attributed this part to what is called social congruency, which means learning in nonthreatening environment where teachers, peers here, have less authority (Loda et al., 2019; Harish \& Nicola, 2017; Henk\& Jos, 1995) $)^{13-15}$.

Most of the participants saw that peers manner match their level of understanding, and peers respond to their concerns, as they know problems and challenges faced them, this reflects cognitive congruency, which means delivering teaching at the same level of learners (Loda et al., 2019; Harish \& Nicola, 2017; Henk\& Jos, 1995) ${ }^{13-15}$.

Regarding the tutor role, a large percentage $(87 \%)$ of interns saw PAL as a beneficial experience for teaching as it decreased their anxiety to inquire in front of others. It improved their professional communication and clinical skills. Studies show that PAL increases confidence for tutors as well as tutees. Using PAL also enhances communication and presentation skills (Usman \& Jamil, 2019) ${ }^{8}$. In addition, PAL gave tutors the opportunity to reflect on their previous experience, this supports previous study which indicates that taking the responsibility to prepare and deliver a lesson increases deep understanding of the task (Cameron et al., 2015) ${ }^{16}$. The interns found PAL as an effective and interesting activity, and they recommended this method to all unit orientation. This is in congruence with other studies where respondents were satisfied with this method and encourage the implementation of this strategy (Usman \& Jamil, 2019; Andrew et al., 2016; Cameron et al., 2015; Bahaa, 2015) $)^{8,12,16,17}$.

\section{Conclusion}

This study emphasizes the importance of social interaction and discussion with peers to enhance clinical training effectiveness. Furthermore, it clarifies the need to find a curricular framework to structure intern training and learning through peers' interaction. In this study, interns found PAL as an effective and interesting activity, and they recommended this method to all unit orientation. So, the situational analysis is an appropriate method for the beginning of any rotation, and we substitute unit orientation by peer assisted orientation.

One of the limitations of this study was the small sample size number, and it would be better to conduct it in comparison with other group, and measure how PAL affects interns' performance in order to prove the cause effect relationship.

\section{References}

1. Paice E, Rutter H, Wetherell M, Winder B,Mcmanus IC. Stressful incidents, stress, and coping strategies in the preregistration house officer year. Medical Education. 2002;36:56-65. https://doi.org/10.1046/j.1365-2923.200 2.01101.x. PMid:11849525.

2. Spencer J. Learning and teaching in the clinical environment. BritishMedicalJournal.2003;326:591-593. https://doi.org/10.1136/bmj.326.7389.591. PMid:12637 408PMCid:PMC1125480.

3. Tim Swanwick. Understanding medical education: Evidence, theory, and practice, Willey Blackwell; 2014. Chapter 8, p. 113. https://doi.org/10.1002/9781118472 361. PMCid:PMC3843076.

4. David Prideaux. $\mathrm{ABC}$ learning and teaching in medicine, BMJ Publishing Group. 2003; 6(7).

5. Marian D ILIE. A Hyper-Rationalistic Model for Curriculum Development: First Draft, Procedia - Social and Behavioral Sciences. 2013; 76:383-387. https://doi. org/10.1016/j.sbspro.2013.04.132.

6. Harish Thampy, Nicola Kersey. Peer assisted learning for foundation learner, John Wiley \& Sons Ltd., and The Association for the Study of Medical Education. The Clinical Teacher. 2017;14:180-183. https://doi. org/10.1111/tct.12586. PMid:27943661.

7. Michael T Ross, Helen S Cameron. Peer assisted learning: a planning and implementation framework: AMEE Guide No. 30. Medical Teacher Journal. 2007; 29:527-54. https://doi.org/10.1080/01421590701665886. PMid:179 78966.

8. Usman R, Jamil B. Perceptions of undergraduate medical students about peer assisted learning Professional. Med. J.2019; 26(8):1283-1288. https://doi.org/10.29309/TP $\mathrm{MJ} / 2019.26 .08 .3870$.

9. Kelly AV. The Curriculum: Theory and Practice. 5th Edition. London, Thousand Oaks, New Delhi: SAGE Publications; 2004. 
10. Dyah Tri Palupi1. What Type of Curriculum Development Models Do We Follow? An Indonesia's 2013 Curriculum Case. IJCETS. 2018; 6(2):98-105. https://doi.org/10.15294/ijcets.v6i2.26954.

11. David M Kaufman. Applying Educational Theory in Practice. In: ABC of learning and teaching in medicine by Blackwell Publishing Ltd.; 2010.p. 1-5.ISBN: 97814 05185974.

12. Andrew Beck, Chanel Wood, Richard Helms, Cynthia Arvizo, Benjamin M Cherry,Nicholas PZiats. PeerAssisted Learning in Introductory Histopathology Improves Learner Scores and Delivers Learner Satisfaction. Med.Sci.Educ.2016;26:85-92. https://doi. org/10.1007/s40670-015-0207-6.

13. Loda T, Erschens R, Loenneker $H$, KeifenheimKE, Nikendei C, JunneF, etal. Cognitive and social congruence in peer-assisted learning - A scoping review. PLoS ONE. 2019;14(9):e0222224. https://doi.org/10.1371/ journal. Pone.0222224. https://doi.org/10.1371/journal. pone.0222224. PMid:31498826 PMCid:PMC6733464.
14. Harish Thampy, Nicola Kersey. Peer Assisted Learning for Foundation Doctors. Clinical Teacher. 2017;14:180183. https://doi.org/10.1111/tct.12586. PMid:27943661.

15. Henk G Schmidt, Jos HC. Moust. What makes a tutor effective: A structural equations modeling approach to learning for teaching in problem curricula. Academic Medicine. 1995;70. https://doi.org/10.1097/00001888199508000-00015. PMid:7646747.

16. Cameron DA, Binnie VI, Sherriff A, Bissell V. Peer assisted learning: Teaching dental skills and enhancing graduate attributes. British Dental Journal. 2015;219(6). https://doi.org/10.1038/sj.bdj.2015.722. PMid:26404990.

17. Bahaa Aba Alkhail. Near-Peer-Assisted Learning (NPAL) in undergraduate medical students and their perception of having medical interns as their near peer teacher. Medical Teacher Journal. 2015;37:S33S39. https://doi.org/10.3109/0142159X.2015.1006602. PMid:25651911. 